\title{
Improvement of the Sterol and Triacylglycerol Compositions of Chemlali Virgin Olive Oils through Controlled Crossing with Mediterranean Cultivars
}

\author{
Hédia Manai-Djebali, 2* , Imen Oueslatii, ${ }^{1,}$, Manuel A. Martínez-Cañas ${ }^{3}$, \\ Mokhtar Zarrouk ${ }^{1,2}$ and Jacinto Sánchez-Casas ${ }^{3}$ \\ ${ }^{1}$ Laboratory of Olive Tree Biotechnology, Centre of Biotechnology of Borj-Cedria (CBBC). B.P. 901, 2050 Hammam-Lif, TUNISIA \\ ${ }^{2}$ University Tunis EI Manar 2092, Tunis, TUNISIA \\ ${ }^{3}$ CICYTEX-Technological Agri-Food Institute (INTAEX), Government of Extremadura, Avenida Adolfo Suaret s/n, E-06007 Badajoz, SPAIN
}

\begin{abstract}
The chemical composition of extra virgin olive oils (EVOOs) from six new progenies, obtained through controlled crossings between the main Tunisian variety Chemlali and autochthonous (Chemcheli) and foreign cultivars (Sigoise, Coratina, Koroneiki, and Arbequina) used as pollen acceptor or pollinator, were compared with the EVOO of Chemlali cultivar known to be the main one cultivated in Tunisia as it is the most adapted to the arid climate. Several analytical determinations of major and minor components of EVOO were employed, especially triacylglycerol and sterol fractions. All the studied hybrid EVOOs showed an improvement in their chemical composition and stability by comparison with Chemlali EVOO. The main triacylglycerols were 1,2,3-trioleylglycerol (OOO), 2,3-dioleyl-1-palmitoylglycerol (POO), 2,3-dioleyl-1linoleylglycerol (LOO) and 2,3-dioleyl-1-stearoylglycerol (SOO). $\beta$-sitosterol, $\Delta 5$-avenasterol and campesterol were the principal sterols in all samples. Cholesterol, stigmasterol, clerosterol and $\Delta 7$ stigmastenol were also found in all samples. Oil samples examined showed inter-variability between the studied cultivars. Results of discriminant and principal component analyses appear to prove that genetic origin of the raw materials has a great influence on the final composition of the oil; especially triacylglycerol and sterol compositions.
\end{abstract}

Key words: controlled crossing, hybrids, improved chemical composition, triacylglycerols, sterols

\section{INTRODUCTION}

Tunisia is one of the countries where the olive oil production has increased fourfold, making it the second largest producer after Spain. Tunisian olive farms cover more than one-third of arable land (More than 1.76 million hectares planted with 74 million olives) contributing to 45 $\%$ of food export receipts, $4.5 \%$ of total exports, and $11 \%$ of the total agricultural production value. The Tunisian olive grove lands, is dominated by two major varieties, 'Chemlali' and 'Chétoui'. Chemlali cultivar is grown in the warm coastal area and low steppes region of the South and the Center of Tunisia. It accounts for nearly $85 \%$ of the area under olive cultivation and for more than $80 \%$ of domestic olive oil production. It shows a high capacity of adaptation to various pedoclimatic conditions ${ }^{1,2)}$. However, the fatty acid composition of its extra virgin olive oil (EVOO) was reported to contain low levels of oleic acid and, therefore, to have low stability against oxidation. To remedy to this situation, several programs have attempted to improve the quality of Chemlali EVOO. Clonal selection programs were carried out to produce olive tree clones through countless asexual propagations ${ }^{3)}$, and a cross breeding programs for a cultivar genetic amelioration. Since 1994, two breeding programs have been carried out within the context of the project "olive breeding" (supported by the International Olive Oil Council(IOOC)). The cultivars Chemlali and Meski have been crossed with both autochthonous and foreign pollinators, yielding 1,600 seedlings which are currently under evaluation ${ }^{4-6)}$. Most of these programs have been focused on cross breeding among the most outstanding cultivars and selection within the progenies ${ }^{7,8)}$. Thus, the improvement of the biochemical composition of Chemlali through controlled crossings should be able to provide hybrids with excellent chemical

\footnotetext{
*Correspondence to: Hédia Manai-Djebali, Centre de Biotechnology of Borj-Cedria, B.P. 901, 2050 Hammam-Lif, TUNISIA

E-mail: Hedia.Manai@cbbc.rnrt.tn

Accepted November 17, 2017 (received for review May 3, 2017)

Journal of Oleo Science ISSN 1345-8957 print / ISSN 1347-3352 online

http://www.jstage.jst.go.jp/browse/jos/ http://mc.manusriptcentral.com/jjocs
} 
profile and a high added value. This step is crucial to determine the range of variation of chemical compounds and the selection of interesting hybrids with a composition within the established limit and to improve the composition of Chemlali olive oil which is usually higher than the maximum permitted limit ${ }^{9)}$.

Following traditional divisions, olive oil contains mainly saponifiable matter made up of triacylglycerols (amounting about $95-98 \%$ of all oil), partial acylglycerols, and esters of fatty acids with saturated fatty alcohols of linear chain, terpenic alcohols and free non-esterified fatty acids. The unsaponifiable matter, which makes up around $2 \%$ of all oils, includes many chemical substances of very different structure, such as triterpenic alcohols and dialcohols, hydrocarbons, phenols and flavonoids, sterols, pigments, tocopherols and volatile compounds ${ }^{10,11)}$. Many of these components have been used for the characterization of olive oils $^{12-14)}$.

Many research were carried out on the controlled crossing of olive cultivars, investigate the resistance of some olive cultivars and hybrids to leaf spot disease ${ }^{15)}$. Crossbreeding programs have been also applied in China and Ukraine for the creation of cultivars better adapted to the local pedo-climatic conditions; in Italy a large cross-breeding program was initiated with the aim of selecting new oil, table or dual-purpose cultivars ${ }^{16)}$. In Turkey, two crossbreeding programs have been initiated and are still in progress to improve early coloring compared to the Memecik cultivar and to obtain new table cultivars with improved fruit characteristics compared to the Gemlik cultivar ${ }^{17)}$.

As part of a genetic improvement program of olive tree through intervarietal breedings to produce superior progeny, several analytical determinations were carried out. This study was conducted to investigate the effect of the controlled crossing on the variation of the triglyceridic and sterolic compositions of the EVOOs of new olive progenies obtained through hybridization between Chemlali and autochthonous and some Mediterranean cultivars used as pollinator or pollen acceptor.

\section{MATERIALS AND METHODS}

\subsection{Chemicals}

$n$-Hexane, diethyl ether, ethanol, methanol and acetone (HPLC Grade)were purchased from Panreac AppliChem (Barcelona, Spain). Potassium hydroxide, Pyridine/hexamethyl-disilazane/trimethylchlorosilane (9:3:1, v/v/v), Folin-Ciocalteau and Sodium Molybdate were obtained from Sigma-Aldrich, Supelco (Bellefonte, PA, USA). Sodium sulphate anhydre, 2,7-dichlorofluorescein, Cholesterol, Campesterol, Stigmasterol, Betulin, $\alpha$-cholestanol, $\beta$-sitosterol standards were purchased from Sigma-Aldrich (St. Louis, MO, USA).

\subsection{Plant material and selected hybrids}

This study was carried out on six olive progenies derived from olive tree seedlings obtained from intervarietal crosses (controlled hybridization) between Chemlali Sfax and other autochthonous (Chemcheli) and foreigner cultivars (Sigoise, Coratina, Koroneiki, and Arbequina) known by their excellent olive oil quality.

The controlled cross-fertilization was carried out mainly by introducing the flowering branches of the pollinating varieties into bags enveloping the female units(Fig. 1). The pollen was transferred three times during the cycle. The bags were removed after full fruit set ${ }^{8}$. The hybrids were obtained from seed germination and plant breeding ${ }^{18)}$, were installed in the experimental station at the Olive Tree Institute of Sfax (Southeast of Tunisia), under the same pedoclimatic conditions.

Three hybrids Hd 031, Hd 044, Hd 045, were obtained by controlled crossings between Chemlali, used as pollen acceptors, and Chemchali(Tunisie), Sigoise(Algeria) and Coratina (Italy), respectively, used as pollinators. The three others progenies Hd 034, Hd 038, and Hd 039 were obtained by crossing between Koroneiki(Greece), Arbequina (Spain), and Coratina (Italy), respectively, used as pollen acceptors, and Chemlali, used as pollinators (Table 1).

The choice of parental varieties used in crosses is based on their adaptation to the arid environment, satisfactory and regular productivity and high oil yield with excellent quality as compared to that of Chemlali ${ }^{8}$. Only healthy olive samples were harvested at the same maturity stage during three consecutive crop seasons.

\subsection{Oil extraction}

Oil extraction was carried out in similar industrial conditions using a laboratory instrument: Abencor analyzer (MC2 Ingenieriay Sistemas, Sevilla, Spain). After harvesting, fresh olives samples were washed, deleafed and then crushed with a hammer mill and were slowly mixed for 30 min. The obtained paste was centrifuged. The oil was separated by decanting, then filtred and stored in the dark glass

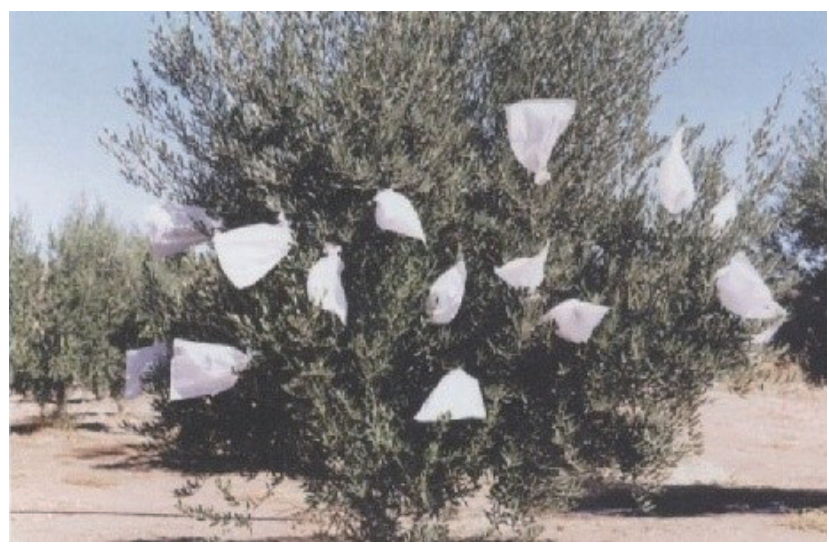

Fig. 1 Controlled crossing technique by bagging. 
Chemical Improvement of EVOO through Controlled Crossings between Cultivars

Table 1 Origin of the parental cultivars used as pollen acceptors(우) or pollinators (ठ $)$ and hybrids obtained through cross breeding.

\begin{tabular}{lcccc}
\hline 우 & $\begin{array}{c}\text { Chemchali } \\
\text { (Tunisia) }\end{array}$ & $\begin{array}{c}\text { Sigoise } \\
\text { (Algeria) }\end{array}$ & $\begin{array}{c}\text { Coratina } \\
\text { (Italy) }\end{array}$ & $\begin{array}{c}\text { Chemlali } \\
\text { (Tunisia) }\end{array}$ \\
\hline Chemlali (Tunisia) & Hd 031 & Hd 044 & Hd 045 & - \\
Koroneiki (Greece) & - & - & - & Hd 034 \\
Arbequina (Spain) & - & - & - & Hd 038 \\
Coratina (Italy) & - & - & - & Hd 039 \\
\hline
\end{tabular}

bottles at $4^{\circ} \mathrm{C}$ until analysis.

\subsection{Analytical methods}

\subsubsection{Determination of oil stability}

Oxidative stability was evaluated by the Rancimat method $^{19)}$. Stability was expressed as the oxidation induction time(h), measured with the Rancimat 743 apparatus (Metrohm Co., Basel, Switzerland), using an oil sample of $3.5 \mathrm{~g}$, warmed to $101.6^{\circ} \mathrm{C}$, and an air flow of $10 \mathrm{~L} \mathrm{~h}^{-1}$.

2.4.2 Determination of polyphenols and o-diphenols content

Total phenol and o-diphenol compounds were colorimetrically quantified ${ }^{20)}$. Phenolic compounds were isolated by triple extraction of a solution of oil in hexane with a water/ methanol mixture $(60: 40, \mathrm{v} / \mathrm{v})$. Total phenols were determined by adding the Folin-Ciocalteu reagent to a suitable aliquot of the combined extracts and measuring the absorbance at $725 \mathrm{~nm} 2 \mathrm{~h}$ later using a UV spectrophotometer (Secomam Anthelie Advanced, Ales Cedex, France). Concentration of total phenols is expressed as the absolute concentration of phenols, calculated according to the response factors determined by Mateos et $a l^{21}{ }^{21}$.

For o-diphenol determination, $5 \mathrm{~mL}$ of phenolic extract were mixed with $1 \mathrm{~mL}$ of a $5 \%$ solution of sodium molybdate dihydrate in ethanol/water $(1: 1, \mathrm{v} / \mathrm{v})$. The mixture was shaken vigorously, and 15 min later the absorbance $370 \mathrm{~nm}$ was measured. Results are expressed as milligrams of caffeic acid per kilogram of oil.

2.4.3 Sterols and triterpenic dialcohols analysis

The qualitative and quantitative sterol contents of the samples were determined according to the European Official Methods as described by Sanchez-Casas et al. ${ }^{22)}$. The lipid, after addition of $\alpha$-cholestanol and betulin as internal standards, was saponified with ethanolic potassium hydroxide solution. The unsaponifiable matter was extracted with diethyl ether. The sterol fraction was separated by Silica gel plate chromatography. The sterols, erythrodiol and uvaol, recovered from the plate were transformed into the corresponding trimethylsilyl ethers and the mixture was analysed by gas chromatography using an HP 6890 gas chromatograph (Hewlett-Packard, Agilent, CA), equipped with a flame ionization detector (FID), a HP-5MS capillary column $(30 \mathrm{~m} \times 0.25 \mathrm{~mm} \times 0.25 \mu \mathrm{m})$ and a 6890 Agilent au- tomatic injector. The working conditions were: injector $300^{\circ} \mathrm{C}$, isothermal analysis at $260^{\circ} \mathrm{C}$, detector temperature $325^{\circ} \mathrm{C}$. Quantification was performed by the internal standard ( $\alpha$-cholestanol) method and results were expressed as $\mathrm{mg} \mathrm{kg}^{-1}$ of oil.

\subsubsection{Triacylglycerol analysis}

The analysis of triacylglycerols was performed according to the official chromatographic method of the European Economic Community Regulations no. 2568/91 ${ }^{23)}$. A Hewlett-Packard high-performance liquid chromatography (HPLC, HP1050, Agilent Technology) quaternary pump instrument equipped with a refractometeric detector was employed using a Lichrosorb RP18 column $(250 \times 4.6 \mathrm{~mm}$, $5 \mu \mathrm{L}$ particle size; Teknocroma, Barcelona, Spain). Settings were: column oven, $45^{\circ} \mathrm{C}$; elution solvent: acetone-acetonitrile $(60: 40, \mathrm{v} / \mathrm{v})$ at a rate of $1.2 \mathrm{~mL} / \mathrm{min}$. The standards used were trilinolein (LLL), triolein (OOO), tripalmitin (PPP), tristearin (SSS), trilinolenin (LnLnLn), and tripalmitolein (PoPoPo) of purity greater than $98 \%$ and purchased from Sigma (St. Louis, MO). The abbreviations used for the fatty acids were Po for palmitoleic, L for linoleic, Ln for linolenic, $\mathrm{O}$ for oleic, $\mathrm{P}$ for palmitic, S for stearic, and A for arachidic. The identification and the determination of the elution order of all triacylglycerols, was made by means of calculation of the equivalent carbon number (ECN) of each triacylglycerols and its reflection in a graph of retention times against the ECN, of triacylglycerols standards, or by chromatograms of reference corresponding to oil soybean, a mixture of soybean oil and olive oil 30:70 and olive oil.

\subsection{Statistical analysis}

The assays were carried out in triplicate. The results are reported as mean values and standard deviations. Significant differences among cultivars were determined by analysis of variance which applied a Tukey's multiple test. Differences were considered statistically significant when probability was greater than $99 \%(p<0.01)$. Triacylglycerol and sterol data were submitted to discriminant and principal component analysis (PCA) in order to classify the samples into groups according to their origins. The statistical analysis was performed using the SPSS 13.0 for windows (SPSS Inc., 2004). 
Table 2 Stability parameters of virgin olive oil from the six new cultivars compared to those of Chemlali variety.

\begin{tabular}{cccc}
\hline \multirow{2}{*}{ Olive Oil Samples } & \multicolumn{3}{c}{ Analytical parameters } \\
\cline { 2 - 4 } & Total phenols $\left(\mathrm{mg} \mathrm{kg}^{-1}\right)$ & $o$-diphenols $\left(\mathrm{mg} \mathrm{kg}^{-1}\right)$ & Oxidative stability (h) \\
\hline Hd 031 & $154.56 \pm 10.17^{\mathrm{c} * \#}$ & $22.71 \pm 1.04^{\mathrm{d} * \#}$ & $47.50 \pm 0.62^{*}{ }^{\mathrm{c}}$ \\
Hd 034 & $332.22 \pm 10.29^{\mathrm{f}}$ & $44.22 \pm 1.32^{\mathrm{f}}$ & $66.38 \pm 1.17^{\mathrm{f}}$ \\
Hd 038 & $152.34 \pm 2.40^{\mathrm{c}}$ & $19.19 \pm 1.03^{\mathrm{bc}}$ & $49.19 \pm 1.14^{\mathrm{cd}}$ \\
Hd 039 & $259.16 \pm 7.87^{\mathrm{d}}$ & $21.43 \pm 2.61^{\mathrm{cd}}$ & $65.07 \pm 1.04^{\mathrm{e}}$ \\
Hd 044 & $302.49 \pm 3.85^{\mathrm{e}}$ & $35.96 \pm 1.34^{\mathrm{e}}$ & $49.34 \pm 0.94^{\mathrm{d}}$ \\
Hd 045 & $135.31 \pm 2.33^{\mathrm{b}}$ & $16.72 \pm 0.58^{\mathrm{b}}$ & $42.12 \pm 0.41^{\mathrm{b}}$ \\
Chemlali & $110.25 \pm 3.43^{\mathrm{a}}$ & $11.41 \pm 1.69^{\mathrm{a}}$ & $25.21 \pm 1.42^{\mathrm{a}}$ \\
\hline
\end{tabular}

${ }^{*}$ Mean $\pm \mathrm{SD}(\mathrm{n}=9)$. Different letters in the same parameter indicate a significant difference at $p<0.01$.

${ }^{\#}$ Concentration expressed as the absolute concentration of phenols, calculated according to the response factors determined by Mateos $e t$ al. $^{21)}$

Table 3 Triacylglycerol composition of studied olive oil samples (Results expressed as percentage of total triacylglycerols).

\begin{tabular}{|c|c|c|c|c|c|c|c|}
\hline \multirow{2}{*}{$\begin{array}{c}\text { Triacylglycerol } \\
(\%)\end{array}$} & \multicolumn{7}{|c|}{ Olive Oil Samples } \\
\hline & Hd 031 & Hd 034 & Hd 038 & Hd 039 & Hd 044 & Hd 045 & Chemlali \\
\hline LLnLn & $0.74 \pm 0.04^{\mathrm{d}} *$ & $0.50 \pm 0.05^{\mathrm{b}}$ & $0.51 \pm 0.08^{b}$ & $0.68 \pm 0.07^{\mathrm{cd}}$ & $0.28 \pm 0.04^{\mathrm{a}}$ & $0.63 \pm 0.04^{\mathrm{c}}$ & $0.27 \pm 0.02^{\mathrm{a}}$ \\
\hline LLL & $0.11 \pm 0.02^{\mathrm{abc}}$ & $0.07 \pm 0.03^{\mathrm{a}}$ & $0.08 \pm 0.04^{\mathrm{ab}}$ & $0.09 \pm 0.03^{\mathrm{ab}}$ & $0.16 \pm 0.06^{\mathrm{c}}$ & $0.14 \pm 0.03^{\mathrm{bc}}$ & $1.50 \pm 0.06^{\mathrm{d}}$ \\
\hline OLLn & $0.26 \pm 0.03^{\mathrm{b}}$ & $0.15 \pm 0.03^{\mathrm{a}}$ & $0.14 \pm 0.02^{\mathrm{a}}$ & $0.28 \pm 0.04^{\mathrm{b}}$ & $0.42 \pm 0.05^{\mathrm{c}}$ & $0.31 \pm 0.03^{\mathrm{b}}$ & $0.47 \pm 0.08^{\mathrm{c}}$ \\
\hline PLLn & $0.06 \pm 0.02^{\mathrm{a}}$ & $0.06 \pm 0.02^{\mathrm{a}}$ & $0.08 \pm 0.04^{\mathrm{a}}$ & $0.05 \pm 0.02^{\mathrm{a}}$ & $0.10 \pm 0.03^{\mathrm{a}}$ & $0.10 \pm 0.03^{\mathrm{a}}$ & $0.36 \pm 0.05^{\mathrm{b}}$ \\
\hline OLL & $2.17 \pm 0.02^{\mathrm{d}}$ & $0.29 \pm 0.04^{\mathrm{a}}$ & $0.53 \pm 0.05^{\mathrm{b}}$ & $1.67 \pm 0.21^{\mathrm{c}}$ & $3.29 \pm 0.12^{\mathrm{f}}$ & $2.51 \pm 0.03^{\mathrm{e}}$ & $7.60 \pm 0.08^{g}$ \\
\hline OLnO & $1.48 \pm 0.07^{\mathrm{b}}$ & $1.13 \pm 0.06^{\mathrm{a}}$ & $1.35 \pm 0.05^{\mathrm{b}}$ & $2.12 \pm 0.09^{\mathrm{d}}$ & $2.11 \pm 0.08^{\mathrm{d}}$ & $1.64 \pm 0.10^{\mathrm{c}}$ & $6.13 \pm 0.76^{\mathrm{e}}$ \\
\hline PLL & $0.45 \pm 0.04^{\mathrm{a}}$ & $0.70 \pm 0.10^{\mathrm{d}}$ & $0.57 \pm 0.06^{\mathrm{bc}}$ & $0.60 \pm 0.05^{\mathrm{bcd}}$ & $0.65 \pm 0.07^{\mathrm{cd}}$ & $0.51 \pm 0.09^{\mathrm{ab}}$ & $0.84 \pm 0.04^{\mathrm{e}}$ \\
\hline OLO & $15.53 \pm 0.29^{d}$ & $4.74 \pm 0.15^{\mathrm{a}}$ & $6.31 \pm 0.10^{\mathrm{b}}$ & $14.54 \pm 0.36^{\circ}$ & $17.75 \pm 0.15^{\mathrm{f}}$ & $15.92 \pm 0.11^{\mathrm{e}}$ & $15.26 \pm 0.05^{\mathrm{d}}$ \\
\hline PLO+SLL & $5.28 \pm 0.08^{\mathrm{d}}$ & $3.16 \pm 0.10^{\mathrm{b}}$ & $2.41 \pm 0.10^{\mathrm{a}}$ & $4.40 \pm 0.38^{\mathrm{c}}$ & $6.27 \pm 0.09^{\mathrm{e}}$ & $6.49 \pm 0.04^{\mathrm{e}}$ & $17.20 \pm 0.09^{\mathrm{f}}$ \\
\hline PPL & $0.33 \pm 0.05^{\mathrm{a}}$ & $0.25 \pm 0.04^{\mathrm{a}}$ & $0.42 \pm 0.07^{\mathrm{ab}}$ & $0.42 \pm 0.05^{\mathrm{ab}}$ & $0.38 \pm 0.09^{\mathrm{ab}}$ & $0.52 \pm 0.04^{\mathrm{b}}$ & $3.55 \pm 0.26^{\mathrm{c}}$ \\
\hline $\mathrm{OOO}$ & $43.48 \pm 0.17^{\mathrm{d}}$ & $35.46 \pm 0.30^{b}$ & $49.19 \pm 0.34^{\mathrm{e}}$ & $43.04 \pm 0.85^{\mathrm{d}}$ & $38.36 \pm 0.20^{\mathrm{c}}$ & $38.71 \pm 0.14^{\mathrm{c}}$ & $15.43 \pm 0.18^{\mathrm{a}}$ \\
\hline $\mathrm{POO}$ & $20.54 \pm 0.27^{\mathrm{b}}$ & $35.76 \pm 0.56^{\mathrm{e}}$ & $19.70 \pm 0.13^{\mathrm{a}}$ & $22.04 \pm 0.26^{\mathrm{d}}$ & $19.30 \pm 0.14^{\mathrm{a}}$ & $21.66 \pm 0.14^{\mathrm{cd}}$ & $21.22 \pm 0.26^{\mathrm{c}}$ \\
\hline PPO & $2.11 \pm 0.30^{\mathrm{a}}$ & $5.45 \pm 0.26^{\mathrm{c}}$ & $2.16 \pm 0.07^{\mathrm{a}}$ & $2.61 \pm 0.15^{\mathrm{b}}$ & $2.25 \pm 0.08^{\mathrm{a}}$ & $2.81 \pm 0.09^{\mathrm{b}}$ & $6.18 \pm 0.08^{\mathrm{d}}$ \\
\hline РPP & $0.95 \pm 0.15^{\mathrm{d}}$ & $0.52 \pm 0.07^{\mathrm{b}}$ & $0.85 \pm 0.08^{\mathrm{d}}$ & $0.66 \pm 0.08^{\mathrm{bc}}$ & $0.55 \pm 0.08^{\mathrm{bc}}$ & $0.68 \pm 0.05^{\mathrm{c}}$ & $0.15 \pm 0.02^{\mathrm{a}}$ \\
\hline SOO & $5.56 \pm 0.23^{\mathrm{c}}$ & $9.27 \pm 0.29^{\circ}$ & $13.42 \pm 0.17^{\mathrm{f}}$ & $5.15 \pm 0.24^{b}$ & $6.60 \pm 0.30^{\mathrm{d}}$ & $5.63 \pm 0.06^{\mathrm{c}}$ & $2.72 \pm 0.25^{\mathrm{a}}$ \\
\hline $\mathrm{SLS}+\mathrm{POS}$ & $0.97 \pm 0.20^{\mathrm{a}}$ & $2.50 \pm 0.46^{\mathrm{c}}$ & $2.29 \pm 0.13^{\mathrm{c}}$ & $1.66 \pm 0.13^{\mathrm{b}}$ & $1.54 \pm 0.11^{b}$ & $1.75 \pm 0.16^{b}$ & $1.15 \pm 0.05^{\mathrm{a}}$ \\
\hline$\Delta \mathrm{ECN} 42^{\S}$ & $0.17 \pm 0.02^{\mathrm{c}}$ & $0.07 \pm 0.03^{\mathrm{a}}$ & $0.16 \pm 0.01^{\mathrm{bc}}$ & $0.07 \pm 0.03^{\mathrm{a}}$ & $0.14 \pm 0.02^{\mathrm{bc}}$ & $0.12 \pm 0.02^{\mathrm{b}}$ & $0.51 \pm 0.04^{d}$ \\
\hline
\end{tabular}

* Mean \pm SD ( $=9$ ). Different letters in the same component indicate a significant difference at $p<0.01$.

${ }^{\S}$ For extra virgin olive oil $\triangle \mathrm{ECN} 42 \leq 0.2^{9)}$

\section{RESULTS AND DISCUSSION}

As far as we know, chemical composition of olive oil is widely influenced by many parameters, including variety, environmental conditions, stage of ripening and extraction technology ${ }^{24)}$. Statistical analysis applied to the different physicochemical parameters (Tables 2, 3 and 4), showed significant differences $(p<0.01)$, pointing the influence of the genetic factor on the chemical characteristics of the studied oils.

\subsection{Oxidative stability and related antioxidants}

The oxidative stability, total phenol and o-diphenol compounds of the different EVOO samples are given in Table 2. Oxidative stability values of the studied EVOOs depended strongly on the genetic factor. All the new progenies exhibited remarkably improved mean values of stability $(>42 \mathrm{~h})$ by comparison with Chemlali cultivar $(25.21 \mathrm{~h})$. The stability of the new cultivar Hd 038 EVOO (obtained from the the crossings between the Arbequina, used as pollen acceptor, 


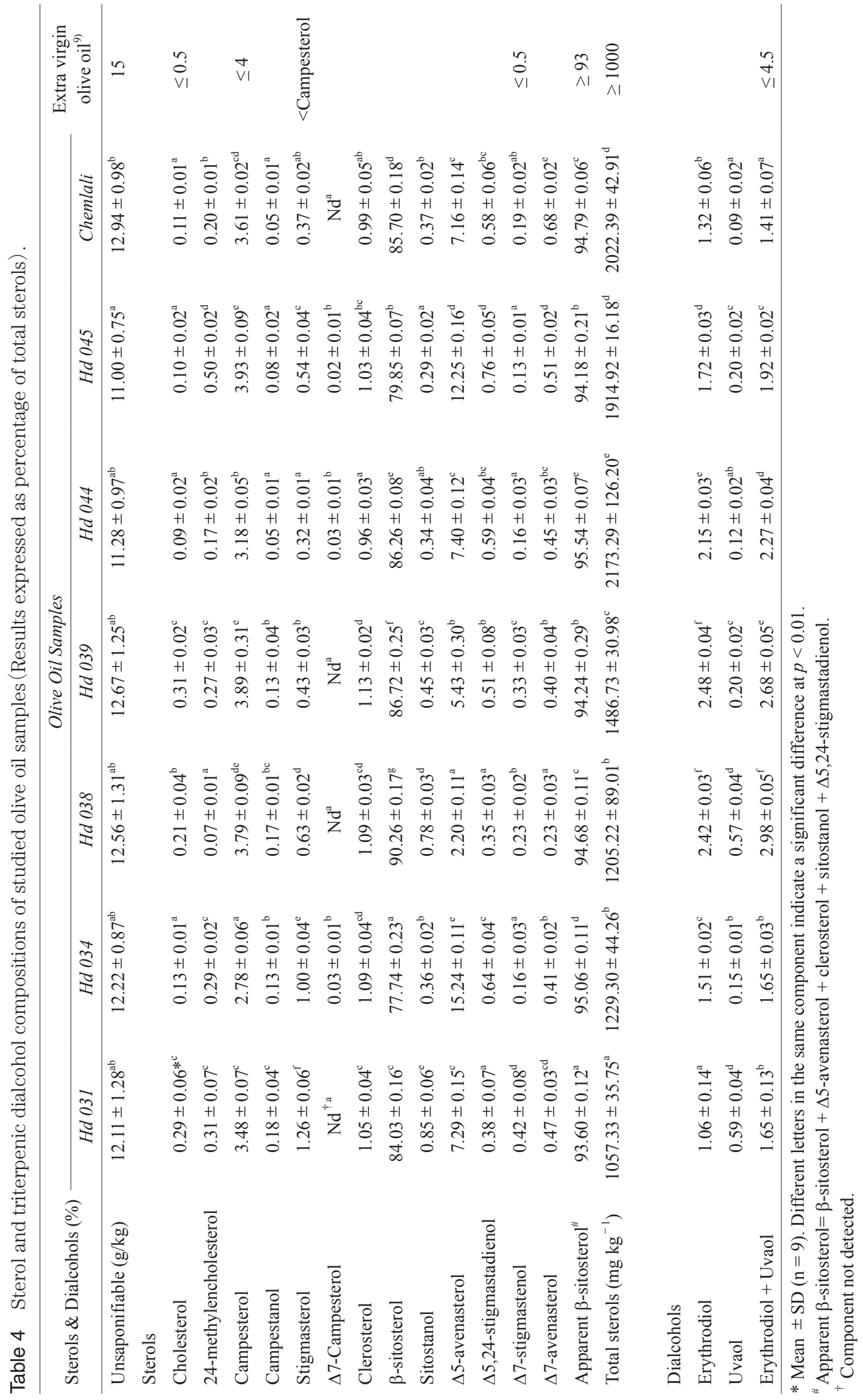




\section{H. M.-Djebali, I. Oueslati, M. A. M.-Cañas et al.}

and the Chemlali cultivar used as pollinator), was similar to that found in the Arbequina monovarietal olive oil ${ }^{25)}$. Moreover, comparison with published data on Italian $\mathrm{EVOOs}^{26}$ indicates that Hd $039 \mathrm{EVOOs}$ (obtained from the crossings between the Coratina cultivar, used as pollen acceptor, and the Chemlali cultivar used as pollinator) showed a stability value $(65.07 \mathrm{~h})$ higher than that of Coratina monovarietal olive oil. It is interesting to mention that Hd 034 (obtained from the crossings between the Koroneiki cultivar, used as pollen acceptor, and the Chemlali cultivar used as pollinator) oil had an oxidative stability value two to threefold higher $(66.38 \mathrm{~h})$ than that of Chemlali. The high oxidative stability of the oil can be explained by the richness of the studied hybrids with antioxidants.

The oxidative stability findings led us to study other compounds that affect EVOO stability. Therefore, the content of total phenols and o-diphenols was examined and shown in Table 2.

As for the oxidative stability, the concentration of total phenols and o-diphenols in the studied EVOOs was strongly affected by the cultivar. The amounts of total phenols and o-diphenols showed significant differences $(p<0.01)$ among the considered olive cultivars.

Phenols play a key role in the shelf life of EVOO due to their biological activity delaying the oxidation processes. In this respect, the primary antioxidants inhibiting oxidation processes in EVOO are phenolic compounds, which act as chain breakers by donating radical hydrogen to alkylperoxyl radicals, produced by lipid oxidation and the formation of stable derivatives during the reaction ${ }^{27}$.

Phenols have been described as the main responsible factors for the oxidative stability of virgin olive oils ${ }^{28,29)}$. Various authors have demonstrated the relationship between such good stability and the oil's total content of phenolic compounds. They studied the levels of contribution of different olive oil constituents on stability and they reported that phenolic compounds appear to have the highest level(approximatively 50\% ${ }^{29)}$.

New progeny oils exhibited total phenol and o-diphenol mean values much higher than those of Chemlali. Hd 034 and Hd 044 EVOOs showed remarkable improvement in the total phenol contents, their values (332.22 and 302.49 $\mathrm{mg} \mathrm{kg}{ }^{-1}$, respectively) are three fold higher than that of Chemlali $\operatorname{EVOO}\left(110.25 \mathrm{mg} \mathrm{kg}^{-1}\right.$ ), whereas, the total phenol contents of the remaining new cultivars showed a weak improvement $\left(>135.31 \mathrm{mg} \mathrm{kg}^{-1}\right)$.

As with the total polar phenols, similar remarkable high level of o-diphenols was observed for $\mathrm{Hd} 034$ and $\mathrm{Hd} 044$ EVOOs which showed values ( 44.22 and $35.96 \mathrm{mg} \mathrm{kg}^{-1}$, respectively) fourfold higher than that of Chemlali EVOO $\left(11.41 \mathrm{mg} \mathrm{kg}^{-1}\right)$. All the remaining new cultivars showed an o-diphenol values varying between 16.72 and $22.71 \mathrm{mg}$ $\mathrm{kg}^{-1}$.

By comparison with literature, the total phenolic com- pounds amount of the new cultivars obtained through crossing are higher than those observed in the monovarietal EVOOs extracted from cultivars used as pollen acceptors or pollinators. Example, for Hd 034 and Hd 038 EVOOs the content of total phenols are higher than those of their corresponding genitors which were Koroneiki (236.48 mg $\mathrm{kg}^{-1}$ ) and Arbequina $\left(108.27 \mathrm{mg} \mathrm{kg}^{-1}\right)$, respectively ${ }^{30}$.

\subsection{Triacylglycerol composition}

The mean values of triacylglycerols (TAGs) for the analysed oils are shown in Table 3. The oils from the studied cultivars are characterized by three primary triacylglycerols: OOO, POO and OLO and seven secondary triacylglycerols: OLL, OLnO, PLO + SLL, PPL, PPO, SOO, and SLS + POS. Small amounts $(\leq 1 \%)$ of OLLn, PLLn, PLL, LLL, LLnLn and PPP were also observed in all samples.

The Triacylglycerol composition presented a significant variability $(p<0.01)$ among cultivars. In the studied oil samples, OOO and POO showed high levels which exceed $57 \%$ of the total TAG profile. Thus, the main TAG, triolein OOO, in the oils of all new olive cultivars, was remarkably high with an amount ranging between $35.46 \%$ observed in Hd 034 and 49.19\% observed in Hd 038. These amounts showed an improvement in the triglyceridic composition by comparison with Chemlali cultivar $(15.43 \%)$. Significant differences $(p<0.01)$ were found between Chemlali and the new cultivars in terms of $\mathrm{OOO}$ content.

Regarding the second important TAG, a wide range of POO can also be noticed, from $19.30 \%$ (Hd 044) to $35.76 \%$ (Hd 034). The EVOOs from Hd 034, Hd 039 and Hd 045 exhibited high level of $\mathrm{POO}$ as compared with that of Chemlali, while the remaining cultivars ( $\mathrm{Hd}$ 031, Hd 038 and Hd 044) were characterized by lower mean values. Regarding the POO content, significant differences $(P<0.01)$ were revealed between olive oil samples, except between Hd 045 and Chemlali.

In general, the TAG composition of the new cultivars obtained through controlled crossing are in good agreement with those described in the literature ${ }^{31}$. The main triacylglycerol components (OOO, POO, and OLO) were similar to those of the most common oils from Spain, Italy and Greece $^{32)}$.

Results of Table 3 showed that triacylglycerol composition and especially OLL, OLO, POL + SLL and SOO were the most useful parameter for discrimination between cul$\operatorname{tivars}(p<0.01)$.

Triacylglycerol composition was established as a measurement of the quality and purity of vegetable oils. The difference between the empirical and theoretical ECN42 triacylglycerol content is a European Union official method since 1997. The obtained results showed that all new cultivars oils have $\triangle \mathrm{ECN} 42$ mean values lower than the maximum limit of 0.2 set by legislation ${ }^{9)}$ while Chemlali oils are characterized by a high mean value of $\triangle \mathrm{ECN} 42$ exceed- 
ing widely the established limit(Table 3 ). Again we note an improvement of $\triangle \mathrm{ECN} 42$ of mean values of the studied progenies as compared to that of Chemlali.

\subsection{Sterols and triterpenic dialcohols}

The unsaponifiable fraction was measured before analysing the sterols and dialcohol compositions. For all studied cultivars content of unsaponifiable matter was usually less than $15 \mathrm{~g} \mathrm{~kg}^{-1}$, maximum limit expected for extra virgin olive oil class (Table 4).

Sterol and alcohol profiles are used to characterize virgin olive oils and especially to detect the adulteration of olive oil with other oils ${ }^{33)}$. It has also been proposed that these profiles can be used to classify virgin olive oils according to their fruit variety ${ }^{34-37)}$. Sterol and triterpenic dialcohol composition of the studied oil samples is shown in Table 4. Regarding the authenticity indices established by the European legislation ${ }^{9)}$, all the analysed oils showed a sterolic and dialcoholic composition within the established limit for extra virgin olive oil category.

Sterols are important constituents of olive oils because they relate to the oil quality. Besides, their determination is of major interest due to their health benefits. The analysis of the sterols by gas chromatography on a capillary column indicated the presence of thirteen sterols. Table 4 shows that the most representative sterols, was $\beta$-sitosterol, $\Delta 5$ avenasterol and campesterol. However, small amounts of cholesterol, stigmasterol, clerosterol and $\Delta 7$-stigmastenol were also found in all samples. The quantitative study of this fraction revealed significant differences in the percentage of sterols among all studied oils. There was a clear predominance of the $\beta$-sitosterol, which is a very interesting sterol from a biological view because it opposes the intestinal absorption of the cholesterol. In fact, it exceeded $77 \%$ in all oil samples, the highest mean value of $\beta$-sitosterol was observed in Hd 038 oil $(90.26 \%)$. Regarding $\Delta 5$ avenasterol content, it was significantly high in Hd 034 $(15.24 \%)$. The antioxidant activity of $\Delta 5$-avenasterol has been pointed out by some works ${ }^{38)}$, thus our results seem to agree with this, since Hd 034 was the most stable oil among the studied samples (Table 2). These two major sterols, $\beta$-sitosterol and $\Delta 5$-avenasterol, were strongly negatively correlated $(p<0.01)$ as the $\Delta$-5-avenasterol is a precursor in the biosynthesis of $\beta$-sitosterol ${ }^{39)}$.

On the other hand, the apparent $\beta$-sitosterol, expressed by the sum of the contents of $\beta$-sitosterol and other four sterols formed by the degradation of $\beta$-sitosterol (sitostanol, $\Delta 5,24$-stigmastadienol, clerosterol and $\Delta 5$-avenasterol), was higher than $93 \%$ in all oil samples tested. This is the regulatory minimum limit, indicative that the sum of the remaining sterols does not surpass $7 \%$, thereby confirming the authenticity of the corresponding oil ${ }^{24)}$.

Stigmasterol is related to various parameters of the quality of virgin olive oil. High levels correlate with high acidity and low organoleptic quality ${ }^{40)}$. The analysed samples presented low levels of stigmasterol, which is indicative that the oil came from healthy fruits and not obtained by systems of forcing ${ }^{41)}$.

In the hybrid oil samples, the $\Delta 7$-avenasterol content changed between 0.23 ( $\mathrm{Hd} 038$ oil) and $0.51 \%$ ( Hd 045 oil); the level of this sterol was significantly high $(p<0.01)$ in Chemlali oil (0.68\%) as compared to the examined hybrids.

Regarding other authenticity indices, established by the legislation ${ }^{9}$, all studied samples respect the established limits: cholesterol and campesterol percentages were below the established limits of 0.5 and $4.0 \%$, respectively. The higher content of campesterol in relation to stigmasterol, described in the literature as a characteristic parameter of virgin olive oils, was confirmed in our research ${ }^{42)}$. Besides, in all cases, total sterols were remarkably higher than the minimum limit set by legislation $\left(1000 \mathrm{mg} \mathrm{kg}^{-1}\right)$, ranging from 1057.33 ( $\mathrm{Hd} 031)$ to $2173.29 \mathrm{mg} \mathrm{kg}^{-1}(\mathrm{Hd}$ 044). This is undoubtedly a good characteristic of olive oils due to the great benefits of these compounds for health.

It is seen that stigmasterol and $\beta$-sitosterol contents were the most useful parameters for discriminating between the studied varieties $(p<0.01)$.

Concerning the levels of triterpenic dialcohols (erythrodiol and uvaol), there was clear differences between analysed oils $(p<0.01)$. The sum of erythrodiol and uvaol in all studied samples respected the established limit of $4.5 \%$ for "extra virgin" olive oil category. The low levels of these dialcohols, generally located in the exocarp of the olive ${ }^{43)}$, confirm once again that the oil samples were obtained from healthy olive fruits.

\subsection{Chemometric analysis}

It is important to note that TAG and sterols are both very important components for the chemical authentication and differentiation of virgin olive oil cultivars. PCA and discriminant analysis (Fig. 2), were applied to triacylglycerols and sterols data (Tables 3 and 4 ) to see whether it was possible to differentiate the olive oil samples according to their variety and to obtain more information on the variables that mainly influence the olive oil samples.

PCA enables us to isolate thirty components intervening differently in variability between oil samples. Five principal component were extracted, they are responsible for $91.6 \%$ of variance; the first three components are enough to explain $76.5 \%$ of data variance. According to the PCA analysis the most contributor parameters to classify olive oil samples according to the cultivar were: OOO, POL + SLL, OLL, OLnO, LLL, PLLn, PPP, PPL, $\Delta 7$-avenasterol, OLLn, Campestanol, SOO, PPO, PLL, LLnLn, Sitostanol, Erythrodiol + Uvaol, Clerosterol and Cholesterol. Those parameters give their variance to the PC1. While $\Delta 5$ avenasterol, $\beta$-sitosterol, POO, $\Delta 7$-Campesterol, $\Delta 5,24$ stigmastadienol, Campesterol and $\Delta 7$-stigmastenol give 
(A)

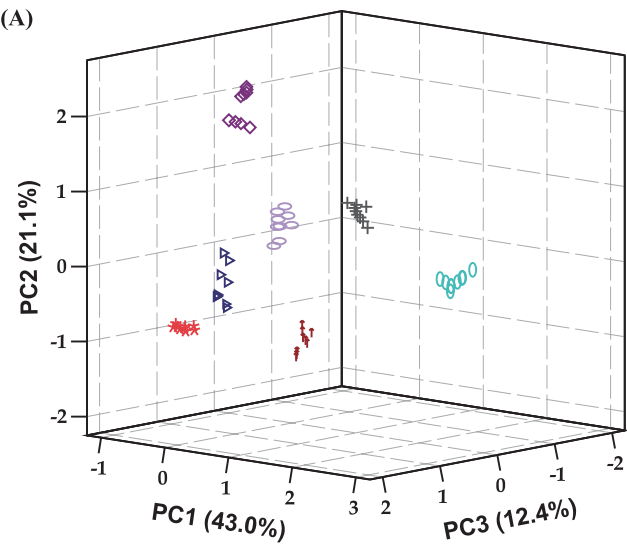

(B)

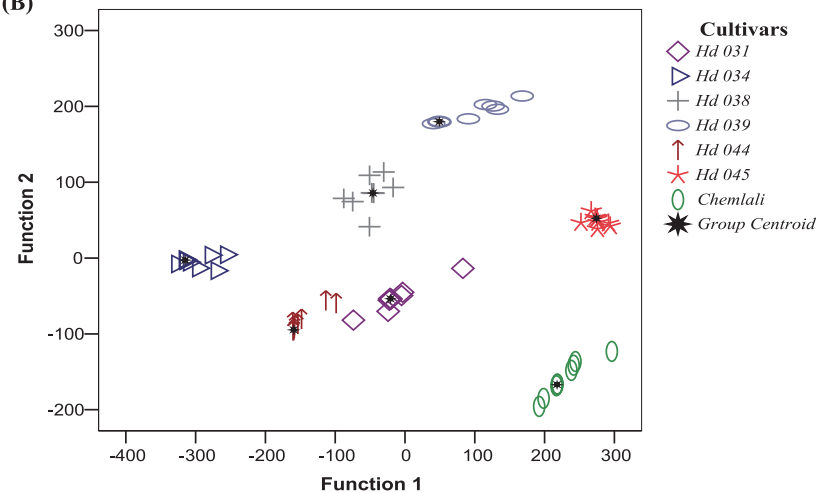

Fig. 2 Principal Component Analysis (A) and Discriminant functions (B) used to classify virgin olive oils by variety according to their sterols and triacylglycerols.

their variance to the PC2. The remaining variables contribute to the other extracted components.

The three-dimensional representation of the first three PC allows a clear separation for analysed samples (Fig. 2A). The examined cultivars were clearly separated according to their triacylglycerol and sterol composition.

Figure 2B displays the results of the discriminant analysis. The oils from distinct cultivars were clearly distinguished. The percentages of correct classification of the samples in base on their cultivar origin were $100 \%$. The first two functions are enough to explain $96.6 \%$ of variance.

These statistical analyses can explain the variability of oil composition according to the cultivar. We note a good discrimination between varieties according to the triacylglycerol and sterol data. These components were also an effective tool for discriminating between crossings.

\section{CONCLUSIONS}

The controlled crossing between Chemlali cultivar and some autochthonous and foreigner cultivars used as pollinator or pollen acceptor produce new progenies characterized by an excellent olive oils in terms of phenolic compounds, oxidative stability, triacylglycerols, sterols and dialcohols and also conform to the norm established by EU Regulations $^{9)}$. Therefore, controlled crossings may be a useful tool for improving the Chemlali olive oil composition since it provides new cultivars adapted to arid climate of southern Tunisia, resistant to the olive tree diseases and with a good oil quality as compared to Chemlali oil which is characterized by low phenolic compounds contents, low oxidative stability and oleic acid and high linoleic and palmitic acids and a high $\triangle \mathrm{ECN} 42$. So, these resistant hybrids can be identified and then used for replanting, or as sources for resistance in future breeding programs.

\section{ACKNOWLEDGEMENTS}

This work was supported by our Ministry of High Education, Scientific Research and Technology. The authors express their sincere gratitude to the personnel of the Laboratories, especially to Mr. Jose M- Garcia Ballesteros, Ms. Julia Barahona Nogales to Ms. Julia Hernandez Carretero, Ms. Salma Nait Mohamed and Ms Zouhour Chalbout.

\section{REFERENCES}

1) Abaza, L.; Msallem, M.; Daoud, D.; Zarrouk, M. Caractérisation des huiles de sept variétés d'olivier tunisiennes. Ol. Corps Gras Lipides 9, 174-179(2002).

2) Baccouri, O.; Cerretani, L.; Bendini, A.; Caboni, M.F.; Zarrouk, M.; Pirrone, L.; Ben Miled, D.D. Preliminary chemical characterization of Tunisian monovarietal virgin olive oils and comparison with Sicilian ones. Eur. J. Lipid Sci. Technol. 109, 1208-1217(2007).

3) Oueslati, I.; Taamalli, W.; Mahjoub Haddada, F.; Manai, H.; Trigui, A.; Zarrouk, M. Improving the fatty acid composition of "Chemlali" virgin olive oil through clonal selection. J. Hortic. Sci. Biotechnol. 84, 155-160 (2009).

4) Manai, H.; Gallardo Gonzalez, L.; Haddada, F.; Sánchez-Casas, J.; Osorio-Bueno, E.; Zarrouk, M. Sensory characteristics of virgin olive oils from monovarietal Tunisian cultivars and hybrids with European varieties. Grasas Aceites 58, 163-169 (2007).

5) Manai, H.; Mahjoub-Haddada, F.; Oueslati, I.; Daoud, D.; Zarrouk, M. Characterization of monovarietal virgin olive oils from six crossing varieties. Sci. Hortic. 115, 252-260 (2008).

6) Rjiba, I.; Dabbou, S.; Gazzah, N.; Hammami, M. Effect of Crossbreeding on the Chemical Composition and Biological Characteristics of Tunisian New Olive Prog- 
enies. Chem. Biodivers. 7, 649-655(2010).

7) Fontanazza, G.; Baldoni, L. Proposal for a program of olive breeding. Ol. Corps Gras Lipides 34, 32-40 (1990).

8) Trigui, A.; Msallem, M. Pollinisation croisée des variétés d'olivier tunisiennes: Chemlali de Sfax et Meski: Résultats préliminaires. Olivae Off. J. Int. Olive Counc. 57, 12-15(1995).

9) EEC. Caractéristiques des huiles d'olive et des huiles de grignons d'olive. J. Off. L'Union Eur. L338, 34-35 (2013).

10) Boskou, D. Olive oil: chemistry and technology. AOCS Press, Champain, IL, pp. 85-127 (1996).

11) Morales, M.; Tsimidou, M. The role of volatile compounds and polyphenols in olive oil sensory quality. in Handbook of Olive Oil: Analysis and Properties, Aspen Publishers, Gaithersburg, MD, pp. 393-458 (2000).

12) Galeano Diaz, T.; Durán Merás, I.; Sánchez Casas, J.; Alexandre Franco, M.F. Characterization of virgin olive oils according to its triglycerides and sterols composition by chemometric methods. Food Control 16, 339347 (2005).

13) Lerma-García, M.J.; Lantano, C.; Chiavaro, E.; Cerretani, L.; Herrero-Martínez, J.M.; Simó-Alfonso, E.F. Classification of extra virgin olive oils according to their geographical origin using phenolic compound profiles obtained by capillary electrochromatography. Food Res. Int. 42, 1446-1452(2009).

14) Pouliarekou, E.; Badeka, A.; Tasioula-Margari, M.; Kontakos, S.; Longobardi, F.; Kontominas, M.G. Characterization and classification of Western Greek olive oils according to cultivar and geographical origin based on volatile compounds. J. Chromatogr. A 1218, 7534-7542 (2011).

15) Ouergui, F.; Fendri, M.; Hannachi, H.; Rassa, N.; Rhouma, A.; Nasraoui, B. Resistance of some olive(Olea europaea) cultivars and hybrids to leaf spot disease analyzed by microsatellites. Int. J. Environ. Agric. Res. 2, 95-92 (2016).

16) Bellini, E.; Giordani, E.; Rosati, A. Genetic improvement of olive from clonal selection to cross-breeding programs. Adv. Hortic. Sci. 22, 73-86 (2008).

17) Yalçinkaya, E.; Kaynaş, N.; Sütçü, A.R.; Fidan, A.E. Olive cross breeding studies at Yalova-Achri. Acta Hortic. 586, 179-182 (2002).

18) Trigui, A. L'amélioration quantitative et qualitative de la production oléicole en Tunisie: L'incontournable nécessité et les perspectives d'une restructuration et d' une amélioration génétique de l'olivier. Olivae Off. J. Int. Olive Counc. 61, 34-40 (1996).

19) Gutiérrez, F. Determination of oxidative stability in virgin olive oils: comparison between Active Oxygen Method and Rancimat Method. Grasas Aceites 40, 1-5
(1989).

20) Ranalli, A.; Ferrante, M.L.; De Mattia, G.; Costantini, N. Analytical evaluation of virgin olive oil of first and second extraction. J. Agric. Food Chem. 47, 417-424 (1999).

21) Mateos, R.; Espartero, J.L.; Trujillo, M.; Ríos, J.J.; León-Camacho, M.; Alcudia, F.; Cert, A. Determination of phenols, flavones, and lignans in virgin olive oils by solid-phase extraction and high-performance liquid chromatography with diode array ultraviolet detection. J. Agric. Food Chem. 49, 2185-2192(2001).

22) Sanchez-Casas, J.; Osorio-Bueno, B.; Montano-Garcia, A.M.; Martinez-Cano, M. Sterol and erythrodiol + uvaol content of virgin olive oils from cultivars of Extremadura (Spain). Food Chem. 87, 225-230 (2004).

23) EEC. Amending Regulation (EEC) No 2568/91 on the characteristics of olive oil and olive-residue oil and on the relevant methods of analysis. Off. J. Eur. Union L 90, 52-70(2013).

24) Stefanoudaki, E.; Kotsifaki, F.; Koutsaftakis, A. Sensory and chemical profiles of three European olive varieties (Olea europea L); an approach for the characterisation and authentication of the extracted oils. $J$. Sci. Food Agric. 80, 381-389 (2000).

25) Mansouri, F.; Ben Moumen, A.; Houmy, N.; Richard, G.; Fauconnier, M.; Sindic, M.; Serghini-Caid, H.; Elamrani, A. Evaluation of the oxidative stability of blends of "Arbequina" olive oils with other monovarietal olive oils. Olivae Off. J. Int. Olive Counc. 120, 23-30 (2014).

26) Cerretani, L.; Baccouri, O.; Bendini, A. Improving of oxidative stability and nutritional properties. AgroFood Ind. Hi-Tech. 19, 21-23 (2008).

27) Servili, M.; Sordini, B.; Esposto, S.; Urbani, S.; Veneziani, G.; Maio, I.D.; Selvaggini, R.; Taticchi, A. Biological activities of phenolic compounds of extra virgin olive oil. Antioxidants 3, 1-23 (2013).

28) Aparicio, R.; Roda, L.; Albi, M.; Gutiérrez, F. Effect of various compounds on virgin olive oil stability measured by Rancimat. J. Agric. Food Chem. 47, 41504155 (1999).

29) Gutiérrez, F.; Arnaud, T.; Garrido, A. Contribution of polyphenols to the oxidative stability of virgin olive oil. J. Sci. Food Agric. 81, 1463-1470 (2001).

30) Allalout, A.; Krichène, D.; Methenni, K.; Taamalli, A.; Oueslati, I.; Daoud, D.; Zarrouk, M. Characterization of virgin olive oil from Super Intensive Spanish and Greek varieties grown in northern Tunisia. Sci. Hortic. 120, 77-83 (2009).

31) Amamou, T. Typology and variability of olive oils according to fruit origins. Ol. Corps Gras Lipides 6, 76-79 (1999).

32) Fedeli, E. Technologie de production et de conservation de l'huile. in Encyclopédie Mondiale de l'Olivi- 
er, Conseil Oléicole International, Madrid(Espagne), pp. 251-291 (1997).

33) Vichi, S.; Pizzale, L.; Toffano, E.; Bortolomeazzi, R.; Conte, L. Detection of hazelnut oil in virgin olive oil by assessment of free sterols and triacylglycerols. $J$. AOAC Int. 84, 1534-1541 (2001).

34) Kyçyk, O.; Aguilera, M.P.; Gaforio, J.J.; Jiménez, A.; Beltrán, G. Sterol composition of virgin olive oil of forty-three olive cultivars from the World Collection Olive Germplasm Bank of Cordoba. J. Sci. Food Agric. 96, 4143-4150 (2016).

35) Manai-Djebali, H.; Krichène, D.; Ouni, Y.; Gallardo, L.; Sánchez, J.; Osorio, E.; Daoud, D.; Guido, F.; Zarrouk, M. Chemical profiles of five minor olive oil varieties grown in central Tunisia. J. Food Compos. Anal. 27, 109-119 (2012).

36) Noorali, M.; Barzegar, M.; Sahari, M.A. Sterol and fatty acid compositions of olive oil as an indicator of cultivar and growing area. J. Am. Oil Chem. Soc. 91, 15711581 (2014).

37) Oueslati, I.; Manai, H.; Mahjoub Haddada, F.; Daoud, D.; Sanchez, J.; Osorio, E.; Zarrouk, M. Dialcohol, and triacylglycerol compounds of extra virgin olive oils from some Tunisian varieties grown in the region of Tataouine. Food Sci. Technol. Int. 15, 5-13(2009).
38) Martínez-Cano, M.A.; De Miguel Gordillo, C.; MendozaFuentes, M.; Martín-Vertedor, D.; Sánchez-Casas, J. The sterol and erythrodiol + uvaol content of virgin olive oils produced in five olive-growing zones of Extremadura(Spain). J. Am. Oil Chem. Soc. 93, 227235 (2016).

39) Clouse, S.D. Arabidopsis mutants reveal multiple roles for sterols in plant development. Plant Cell 14, 19952000 (2002).

40) Gracia-Gómez, M.S. Chemical composition of virgin olive oil "Empeltre" variety from the Bajo Aragón region. Grasas Aceites 52, 52-58(2001).

41) Koutsaftakis, A.; Kotsifaki, F.; Stefanoudaki, E. Effect of extraction system, stage of ripeness, and kneading temperature on the sterol composition of virgin olive oils. J. Am. Oil Chem. Soc. 76, 1477-1481 (1999).

42) Phillips, K.M.; Ruggio, D.M.; Toivo, J.I.; Swank, M.A.; Simpkins, A.H. Free and esterified sterol composition of edible oils and fats. J. Food Compos. Anal. 15, 123-142 (2002).

43) Christopoulou, E.; Lazaraki, M.; Alexiou, F.; Synouri, S.; Frangiscos, E. Influence of certain factors on the composition of olive-pomace oils. Part II. Sterols, triterpenic dialcohols and aliphatic alcohol. Riv. Ital. Delle Sostanze Grasse, 73, 201-211(1996). 